UCRL-ID-129281

\title{
Radionuclide Transport Through Engineered Barrier System Alteration Products
}

B.E. Viani

P.C. Torretto

S.L. Matzen

December 1997

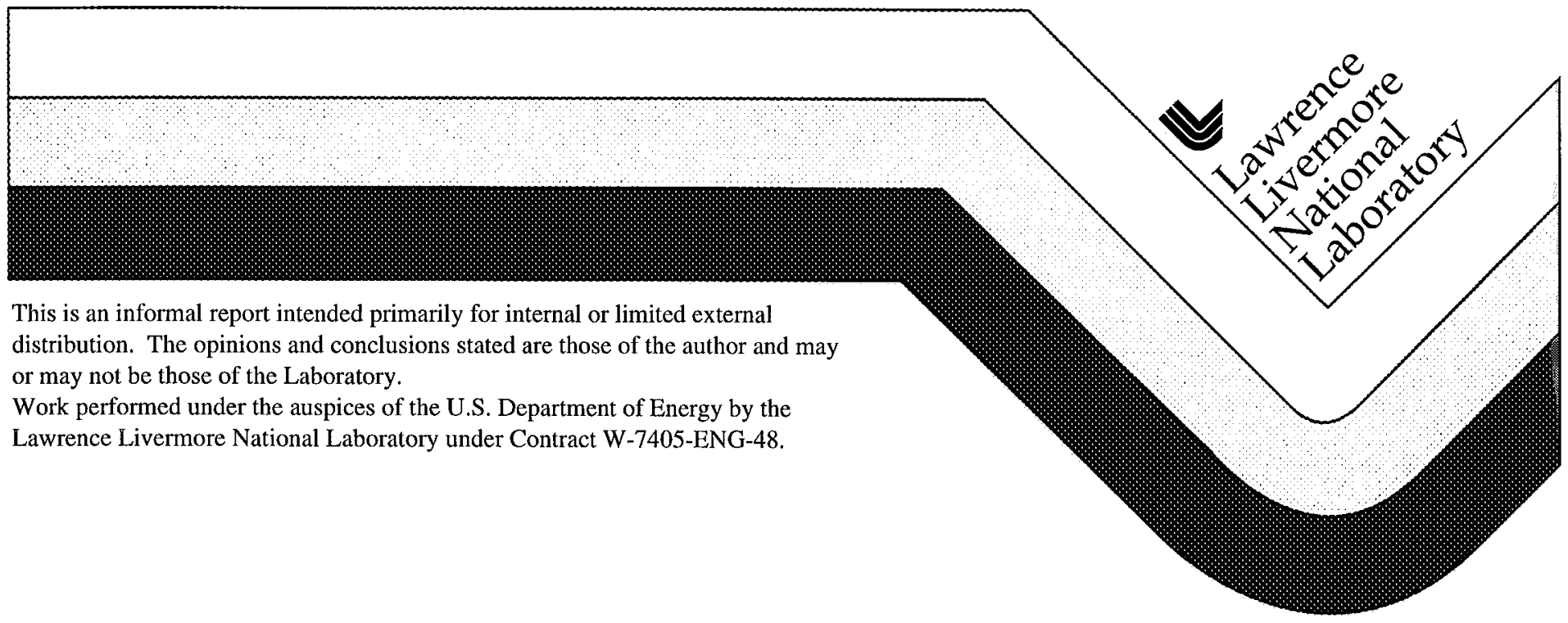




\section{DISCLAIMER}

This document was prepared as an account of work sponsored by an agency of the United States Government. Neither the United States Government nor the University of California nor any of their employees, makes any warranty, express or implied, or assumes any legal liability or responsibility for the accuracy, completeness, or usefulness of any information, apparatus, product, or process disclosed, or represents that its use would not infringe privately owned rights. Reference herein to any specific commercial product, process, or service by trade name, trademark, manufacturer, or otherwise, does not necessarily constitute or imply its endorsement, recommendation, or favoring by the United States Government or the University of California. The views and opinions of authors expressed herein do not necessarily state or reflect those of the United States Covernment or the University of California, and shall not be used for advertising or product endorsement purposes.

This report has been reproduced directly from the best available copy.

Available to DOE and DOE contractors from the

Office of Scientific and Technical Information

P.O. Box 62, Oak Ridge, TN 37831

Prices available from (423) 576-8401

Available to the public from the National Technical Information Service

U.S. Department of Commerce 5285 Port Royal Rd.,

Springfield, VA 2216 


\title{
Radionuclide Transport Through Engineered Barrier System
} Alteration Products

\author{
Milestone SPL3FM4
}

B.E. Viani, P.C. Torretto, and S.L. Matzen

LLNL 


\section{Introduction}

\section{Rationale}

The primary rationale for studying the transport behavior of radionuclides through the Engineered Barrier System/Near Field Environment (EBS/NFE) is to ascertain whether the material properties of the introduced and altered host rock can significantly affect the transport of radionuclides from the waste container to the far field. That is, does the EBS/NFE have a significant impact on the performance of the repository by altering radionuclide flux after containment has been breached?

\section{Judging Impact}

For an EBS/NFE component to play an important role in repository performance with respect to radionuclide release, its physical and/or chemical properties must have the potential to significantly affect:

The longevity of the waste container

The hydrologic regime at the waste container

Radionuclide solubility

Radionuclide partitioning between solution and solid

The generation and/or stability of colloids

The transport of radionuclides away from the container

In addition, the EBS/NFE component must be present in quantities great enough to be significant, must be situated in a position to affect radionuclide transport or water contact mode, and must either retain its significant properties or develop them during the hydrothermal regime that will obtain during the period of substantially complete containment.

\section{Scope}

The intent of this report is to present data and modeling results that can be used to assess the importance of canister corrosion products and cementitious materials to the transport of radionuclides to the far field. Published data and preliminary experimental and modeling derived data for U sorption on hematite (Viani and Torretto, 1997) will be used as an example to assess the potential for corrosion products to significantly affect repository performance for cationic radionuclides such as $\mathrm{Pu}, \mathrm{U}, \mathrm{Np}$, and $\mathrm{Th}$. Because radionuclide transport experiments using cementitious materials are not yet complete, this analysis will not include transport results for concretes but will provide information 
regarding the current status of experiments and a preliminary assessment of the effect of concrete chemistry on the transport of $U$ through hematite corrosion products.

The specific effects of colloidal transport, intermittent flow, unsaturated flow, and extremes in temperature, ionic strength, and solution chemistry have not been addressed at this time. Transport of anionic radionuclides such as I and Tc are not addressed. Experiments using $\mathrm{I}^{-}$have shown that it behaves conservatively in tuff (Viani and Carman, 1995) and in quartz/hematite mixtures (Viani and Torretto, 1997). However, there are data that suggest $\mathrm{I}^{-}$may sorb on concrete, and therefore, may not be conservative (Atkins and Glasser, 1990; Baker et al., 1994; Heath et al., 1996). For corrosion products and concretes, experiments and modeling are continuing, and a more complete description of their radionuclide transport properties will be incorporated into the Near Field Environment Models Report.

\section{Waste Package Canister Corrosion Products}

Based on proposed designs for waste canisters, between 1.6 and $2.0 \times 10^{4} \mathrm{~kg}$ of corrosion allowance steel will surround each canister. It is expected that the corrosion allowance steel will alter primarily to iron oxide during the post-emplacement dryout and rehydration phase (hydrothermal period) of the repository (Viani, 1996). Depending on the specific oxide formed, the maximum mass of iron oxide that could be formed from each canister would range from 2.2 to $3.9 \times 10^{4} \mathrm{~kg}$.

\section{Simple bounding calculation of radionuclide retardation}

Can the corrosion allowance material serve as a significant barrier to radionuclide transport? Iron oxides are effective sorbents for cationic radionuclides such as $\mathrm{U}, \mathrm{Np}, \mathrm{Pu}$, and $\mathrm{Th}$, and thus could potentially significantly retard these radionuclides. In order to bound the potential for radionuclide retardation, an upper limit to the radionuclide sorbed by a given mass of corrosion product can be estimated based on the maximum sorption site density and the surface area of the sorbent.

The maximum site densities estimated for iron oxides from measurements of adsorption maxima and estimates of proton donor/acceptor sites ranges between $\sim 2$ and 7 sites $/ \mathrm{nm}^{2}$ for cationic sorbates (Davis and Kent, 1990; Dzombak and Morel, 1990). Surface areas of natural and synthesized iron oxides vary widely, but in general, natural and/or poorly ordered synthetic oxides have relatively large specific surfaces (on the order of tens to hundreds of $\mathrm{m}^{2} / \mathrm{g}$ ) (Davis and Kent, 1990; Dzombak and Morel, 1990). Assuming a maximum sorption site density of 2.31 sites $/ \mathrm{nm}^{2}$ (Dzombak and Morel, 1990), and a specific surface of $20 \mathrm{~m}^{2} / \mathrm{g}$ (Davis and Kent, 1990), and considering $U$ as the sorbate, the site density limited sorption would be $\sim 0.02 \mathrm{~g} \mathrm{U} / \mathrm{g}$ oxide ( $\sim 550 \mathrm{~kg} \mathrm{U}$ per container). Depending on actual site densities and surface areas, this value could vary by an order of magnitude in either direction. 
Sorption may be also be limited to a value less than the maximum site density when the solid/liquid partition coefficient $\left(\mathrm{K}_{d}\right)$ is less than some critical value. When the $\mathrm{K}_{d}$ is below this value, a radionuclide-bearing groundwater will "breakthrough" a sorbing layer (i.e., exit at its inflow concentration) even though all potential sorption sites have not been filled.

A simple calculation of the years for a radionuclide-bearing fluid to exceed the sorption capacity (either site density or $\mathrm{K}_{\mathrm{d}}$-limited) of a corrosion layer was made based on the following assumptions:

The maximum sorption density is 2.31 sites $/ \mathrm{nm}^{2}$.

The specific surface of the oxides in the corrosion layer is $20 \mathrm{~m}^{2} / \mathrm{g}$.

Sorption is linear and is defined by a constant $\mathrm{K}_{\mathrm{d}}$.

$\mathrm{Six} \mathrm{L/yr}{ }^{1}$ of groundwater contact the waste from one canister.

The concentration of radionuclide in the groundwater after contacting the waste is 1 $\mathrm{mg} / \mathrm{L}$.

The radionuclide-bearing groundwater contacts a fraction of $3 \times 10^{4} \mathrm{~kg}$ of iron oxide corrosion product that surrounds the waste.

Figure 1 shows the time it would take for a radionuclide to breach the corrosion product layer for sorption $\mathrm{K}_{\mathrm{d}}$ 's varying between $10^{2}$ and $10^{5} \mathrm{~mL} / \mathrm{g}$ and fractional contact volumes between 0.01 and 0.20 . For $K_{d}$ 's below $\sim 10^{4} \mathrm{~mL} / \mathrm{g}$, breakthrough is determined by $\mathrm{K}_{\mathrm{d}}$. Above that value, breakthrough is determined by the maximum site density. Partition coefficients on the order of $10^{3}-10^{6} \mathrm{~mL} / \mathrm{g}$ for $\mathrm{U}$ on iron oxides have been experimentally measured at low sorbent to solution ratios $(\sim 1 \mathrm{~g} / \mathrm{L})$ at $\mathrm{pH}$ 's between 5 and 9 (Turner, 1995; Ticknor, 1994). For $\mathrm{K}_{\mathrm{d}}$ 's greater than $\sim 10^{3} \mathrm{~mL} / \mathrm{g}$ and volume fractions greater than 0.01 , the calculation suggests that retardation would be on the order of thousands to hundreds of thousands of years. These retardation times imply that the corrosion layer can have a dramatic effect on the performance of the repository; especially for long lived radionuclides such as $\mathrm{Np}$.

\section{1-D flow and transport calculation of radionuclide retardation}

A simple site- or $\mathrm{K}_{\mathrm{d}}$-limited mass balance model cannot account for either the solution or surface chemical effects that have been shown to strongly influence sorption onto iron oxides (Dzombak and Morel, 1990). Solution composition, particularly $\mathrm{pH}$ and dissolved $\mathrm{CO}_{2}$ can dramatically alter the partitioning of radionuclides between solution and surface. Mineral surface heterogeneity, especially the presence of a small proportion of sites with a high affinity for the sorbate metal (strong sites) can result in $\mathrm{K}_{\mathrm{d}}$ 's that vary with the

\footnotetext{
1 Calculated using the following assumptions: percolation flux $6 \mathrm{~mm} / \mathrm{yr}$; one third of flux via fractures; $10 \%$ of fracture flow intersects drifts; each waste package intercepts flow area equal to twice its width and length; i.e., $30 \mathrm{~m}^{2}$.
} 
ratio of the mass of sorbent to mass of sorbate. The simple $K_{d}$ approach can not account for competition for sorption sites by other metals, or prior "passivation" of the sorbent (i.e., saturation of sorption sites by other sorbates). Of the variables listed above, $\mathrm{pH}$, fugacity of $\mathrm{CO}_{2}$, competing cations, and ratio of sorbent to sorbate are likely to be the most important variables controlling sorption of $\mathrm{U}, \mathrm{Np}, \mathrm{Pu}$, and other hydrolyzable

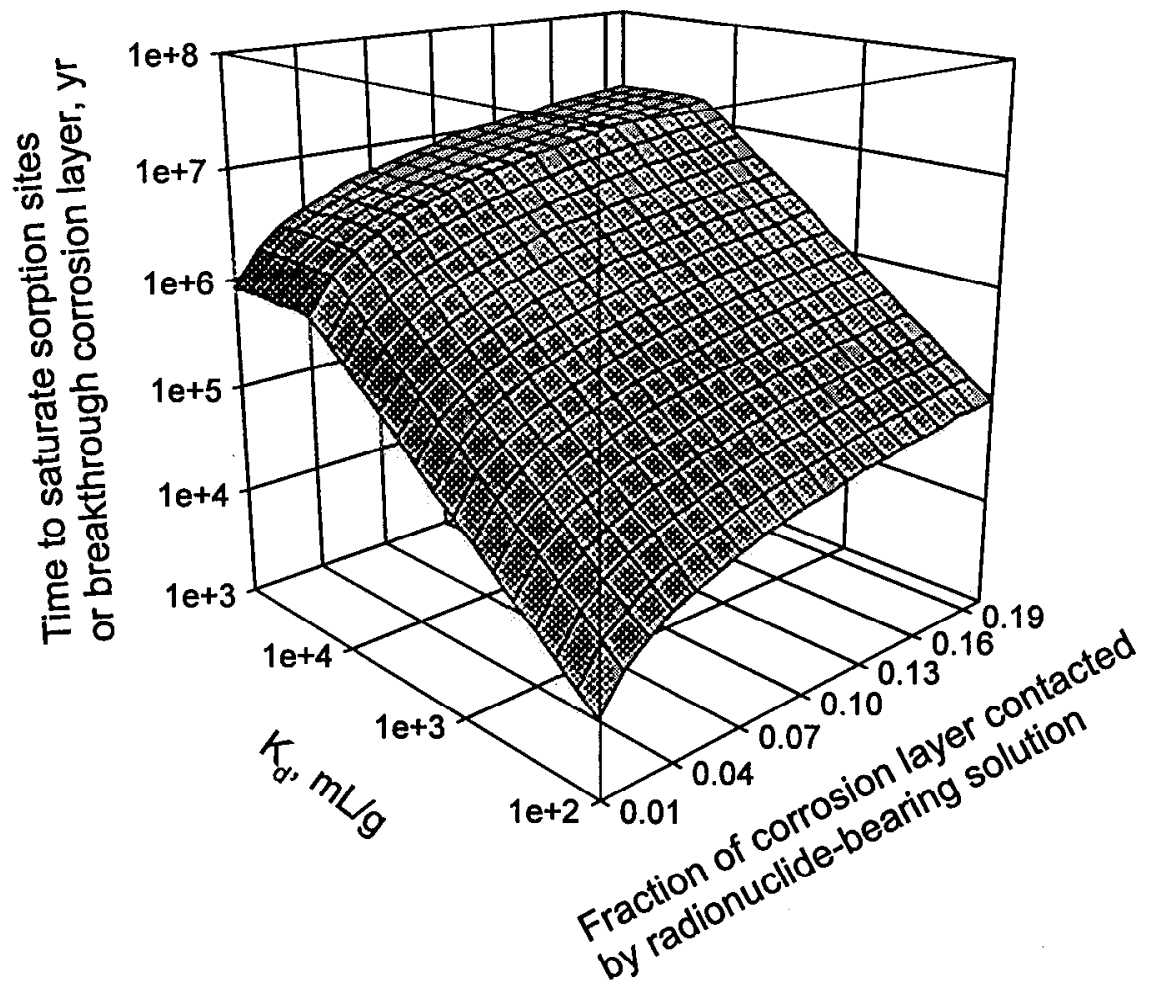

Figure 1. Calculated years to breakthrough of radionuclide-bearing groundwater through corrosion layer as a function of $\mathrm{K}_{\mathrm{d}}$ and volume-fraction of the corrosion product from one waste canister $(\sim 30000 \mathrm{~kg})$ contacted by the groundwater. (Assumptions: $6 \mathrm{~L}$ groundwater containing $1 \mathrm{mg} / \mathrm{L}$ radionuclide intercepts a fraction of the corrosion layer of each canister each year; the maximum adsorption is limited by an adsorption site density of 2.31 sites $/ \mathrm{nm}^{2}$ and a specific surface of $20 \mathrm{~m}^{2} / \mathrm{g}$; sorption follows a linear isotherm)

cations under the oxidizing conditions expected in the potential repository. To account for these effects, a more complex model that considers specific solution and mineral surface/radionuclide interaction was used in combination with a 1-D transport code to simulate transport through a hypothetical corrosion layer composed of hematite.

Surface Complexation Model - A surface complexation model (SCM) was used to simulate sorption. Dzombak and Morel (1990) and Turner (1995) showed that the diffuse 
double layer model (DLM), the simplest of the SCM's, is capable of effectively modeling a wide variety of metal-surface interactions. For each type of sorption site, equilibrium constants for 2 protonation reactions (acidity constants), the site density, and equilibrium binding constants for each sorbing species are required. We used published acidity constants and total site density that have been shown to be effective in modeling adsorption of radionuclides on iron oxides and other phases (Turner, 1995).

The sorption of uranium was modeled by assuming only one monodentate surface species could form (Turner, 1995). Turner (1995) showed that this assumption was sufficient for modeling $U$ sorption onto iron oxide and other mincrals over a relatively wide range of experimental values. For this analysis we simulated the effect of surface heterogeneity by including a small fraction ( 0.0325$)$ of strong sites. The presence of these sites was inferred from $U$ transport experiments (Viani and Torretto, 1997).

Though relatively simple, the DI,M model contains features that allow for the effects of $\mathrm{pH}$, competing adsorption, and variable sorbent/sorbate ratios on uranium adsorption. The DLM model requires equilibrium constants for the following reactions:

$\begin{array}{llll}>\mathrm{FeOH}^{\circ} & = & >\mathrm{FeO}^{-}+\mathrm{H}^{+} & \mathrm{K} \\ >\mathrm{FeOH}^{\mathrm{o}}+\mathrm{H}^{+} & = & >\mathrm{FeOH}_{2}^{+} & \mathrm{K}_{+} \\ >\mathrm{FeOH}^{\circ}+2 \mathrm{H}_{2} \mathrm{O}+\mathrm{UO}_{2}^{++} & = & >\mathrm{FeOUO}_{2}(\mathrm{OH})_{2}^{-}+3 \mathrm{H}^{+} & \mathrm{K}_{\mathrm{B}}\end{array}$

where $>\mathrm{FeOH}^{\circ}$ signifies the surface site, and $\mathrm{K}_{.}, \mathrm{K}_{+}$, and $\mathrm{K}_{\mathrm{B}}$ are the deprotonation, protonation, and binding constant, respectively. The effects of electrostatic interactions are explicitly provided for in the formulation of the surface binding equilibrium constants (Dzombak and Morel, 1990). A one-dimensional reactive transport code, X1t (Bethke, 1996), that simulates advective, diffusive, and dispersive transport while accounting for chemical changes due to precipitation/dissolution, surface complexation (DLM), and solution speciation, was used to simulate transport of $U$ through a corrosion layer composed of hematite.

Transport Simulations - X1t simulations use the method of operator splitting by which the calculation of mass transfer is performed separately from the chemical aspects of the computation. The physical and chemical parameters used in the simulations are shown in Table 1 . The $\mathrm{K}_{\mathrm{B}}$ value for the weak sites was derived by varying $\mathrm{K}_{\mathrm{B}}$ until model prediction fit batch sorption data for $U$ on hematite at room temperature (Viani and Torretto, 1997). The $K_{B}$ for the strong site was arbitrarily set at 4 orders of magnitude stronger than $\mathrm{K}_{\mathrm{B}}$ for the weak site. This is consistent with observed differences in site binding constants for transition metals on iron oxides that differ by 3-4 orders of magnitude. The fraction of strong sites was inferred by varying the site density until the simulated U breakthrough curve fit the experimental data (Viani and Torretto, 1997). 
Table 1. Summary of parameters used to simulate transport of $U$ through hematite corrosion layer.

\begin{tabular}{|c|c|c|}
\hline \multicolumn{3}{|c|}{ Properties of Flow System } \\
\hline & Medium & Hematite \\
\hline & Fractional porosity & 0.40 \\
\hline & Specific discharge, $\mathrm{cm} / \mathrm{yr}$ & 2.1 \\
\hline & Flow path length, $\mathrm{m}$ & 1 \\
\hline & Dispersivity, $\mathrm{m}$ & 0.01 \\
\hline & Diffusion coefficient, $\mathrm{cm}^{2} / \mathrm{s}$ & $1 \times 10^{-6}$ \\
\hline & Simulation time, yr & $3 \times 10^{4}$ \\
\hline & Number of nodes & 5 \\
\hline & Limiting Courant number & 1 \\
\hline \multicolumn{3}{|c|}{ Properties of Hematite Sorbent } \\
\hline & Specific surface, $\mathrm{m}^{2} / \mathrm{g}$ & 20 \\
\hline \multirow{4}{*}{ Weak Sites } & Site density, sites $/ \mathrm{nm}^{2}$ & 2.235 \\
\hline & $\log K_{+}$ & 7.35 \\
\hline & $\log K$ & -9.17 \\
\hline & $\log K_{B}$ & -11.7 \\
\hline \multirow{4}{*}{ Strong Sites } & Site density, sites $/ \mathrm{nm}^{2}$ & 0.075 \\
\hline & $\log \mathrm{K}_{+}$ & 7.35 \\
\hline & $\log K$ & -9.17 \\
\hline & $\log K_{B}$ & -7.7 \\
\hline
\end{tabular}

The simulations were designed to obtain a sense of the importance of the phenomena rather than bound all possible groundwater compositions. Five different simulated fluids were used to assess the sensitivity of $U$ transport to $\mathrm{pH}$ and dissolved $\mathrm{CO}_{2}$ (Table 2). The range in $\mathrm{pH}$ and ionic strength considered largely spans the range displayed by Yucca Mountain groundwaters, but does not encompass $\mathrm{pH}$ extremes that might arise due to interaction of fluids with fresh concretes or microbiologically induced acidity. However, the $\mathrm{pH}$ values considered do span the range over which dissolved $\mathrm{CO}_{2}$ varies from being less important (low $\mathrm{pH}$ ) to where it is very significant (high $\mathrm{pH}$ ) with respect to $\mathrm{U}$ transport. The fugacity of $\mathrm{CO}_{2}$ was varied between 0 and approximately 10 -fold greater than atmospheric $(10 \mathrm{x} \mathrm{atm}$; fugacity $=0.003)$. Ionic strength varied as necessary to maintain electrical balance at the given $\mathrm{pH}$. 
Table 2. Composition of five U-bearing groundwaters used to simulate transport of $U$ through hematite corrosion products.

\begin{tabular}{|c|c|c|c|c|c|}
\hline \multirow[b]{2}{*}{$\begin{array}{l}\text { Inlet Fluid } \\
\text { Composition }\end{array}$} & \multicolumn{5}{|c|}{ Simulation } \\
\hline & $\begin{array}{c}\mathrm{pH} 6, \\
\text { no } \mathrm{CO}_{2}\end{array}$ & $\begin{array}{c}\mathrm{pH} \mathrm{6} \\
\mathrm{atm} \mathrm{CO}_{2}\end{array}$ & $\begin{array}{c}\mathrm{pH} \mathrm{8} \\
\text { no } \mathrm{CO}_{2}\end{array}$ & $\begin{array}{c}\mathrm{pH} \mathrm{8} \\
\mathrm{atm} \mathrm{CO}_{2}\end{array}$ & $\begin{array}{c}\mathrm{pH} \mathrm{8} \\
10 \times \mathrm{CO}_{2}\end{array}$ \\
\hline $\mathrm{pH}$ & 6 & 6 & 8 & 8 & 8 \\
\hline $\mathrm{CO}_{2}$, fugacity & 0 & 0.003 & 0 & 0.0003 & 0.003 \\
\hline $\mathrm{O}_{2}$, fugacity & 0.20 & 0.20 & 0.20 & 0.20 & 0.20 \\
\hline $\begin{array}{l}\text { Ionic } \\
\text { strength, M }\end{array}$ & 0.11 & 0.11 & 0.01 & 0.01 & 0.01 \\
\hline $\mathrm{U}, \mathrm{M}$ & $4 \times 10^{-6}$ & $4 \times 10^{-6}$ & $4 \times 10^{-6}$ & $4 \times 10^{-6}$ & $4 \times 10^{-6}$ \\
\hline
\end{tabular}

Uranium transport was simulated because there are extensive data sets in the literature and we have experiments in our laboratory which address the issue of site heterogeneity as it pertains to transport through hematite/quartz mixtures (Viani and Torretto, 1997). It's expected that because the adsorption of neptunium $(\mathrm{Np})$ onto iron oxides is similar to $\mathrm{U}$ (Turner, 1995), simulations using $\mathrm{U}$ should give a reasonable idea of what might be expected with $\mathrm{Np}$. The concentration of $U$ in solution was set to $\sim 1 \mathrm{mg} / \mathrm{L}\left(4 \times 10^{-6} \mathrm{M}\right)$ to allow comparison with the results based on the simple mass balance calculation presented above. Current experiments using $\mathrm{Np}$ will provide surface complexation parameters and assess the role of site heterogeneity to be used in subsequent modeling.

Compared batch sorption experiments, the ratio of sorbent to sorbate in a sediment or rock (for any given volume element) is much larger and is controlled by the porosity of the medium (for a saturated medium). For these simulations the ratio of sorbent to solution is $\sim 7875 \mathrm{~g} / \mathrm{L}$, almost 4 orders of magnitude larger than most laboratory experiments. Under conditions of unsaturated flow (for a given specific discharge and porosity) this ratio would be even larger.

Simulation Results - In Figure 2, the concentration of U (C) relative to its influx concentration $(\mathrm{Co})$ is shown at $10 \mathrm{~cm}$ into the corrosion layer for the five different influent solutions. Only one solution, $\mathrm{pH}, 10 \mathrm{x}$ atm $\mathrm{CO}_{2}$, is close to breaking through after $3 \times 10^{4}$ years $(\mathrm{C} / \mathrm{Co} \sim 0.8)$. Under these flow conditions, a conservative (non-retarded) species would be expected to breakthrough in about 20 years. As expected, $\mathrm{CO}_{2}$ concentrations have little effect on $\mathrm{U}$ transport at $\mathrm{pH} 6$, but significantly affect transport at $\mathrm{pH} 8$.

At all other nodes (Figures 3-5) $\mathrm{U}$ concentrations are very low, and $\mathrm{C} / \mathrm{Co}$ are less that $10^{-5}$ except for the $\mathrm{pH} 8,10 \mathrm{x}$ atm $\mathrm{CO}_{2}$ fluid at $30 \mathrm{~cm}(\mathrm{C} / \mathrm{Co} \sim 0.01)$. Under the given conditions, $\mathrm{U}$ breakthrough for distances greater than $30 \mathrm{~cm}$ will not occur for thousands of years in excess of $3 \times 10^{4}$. 


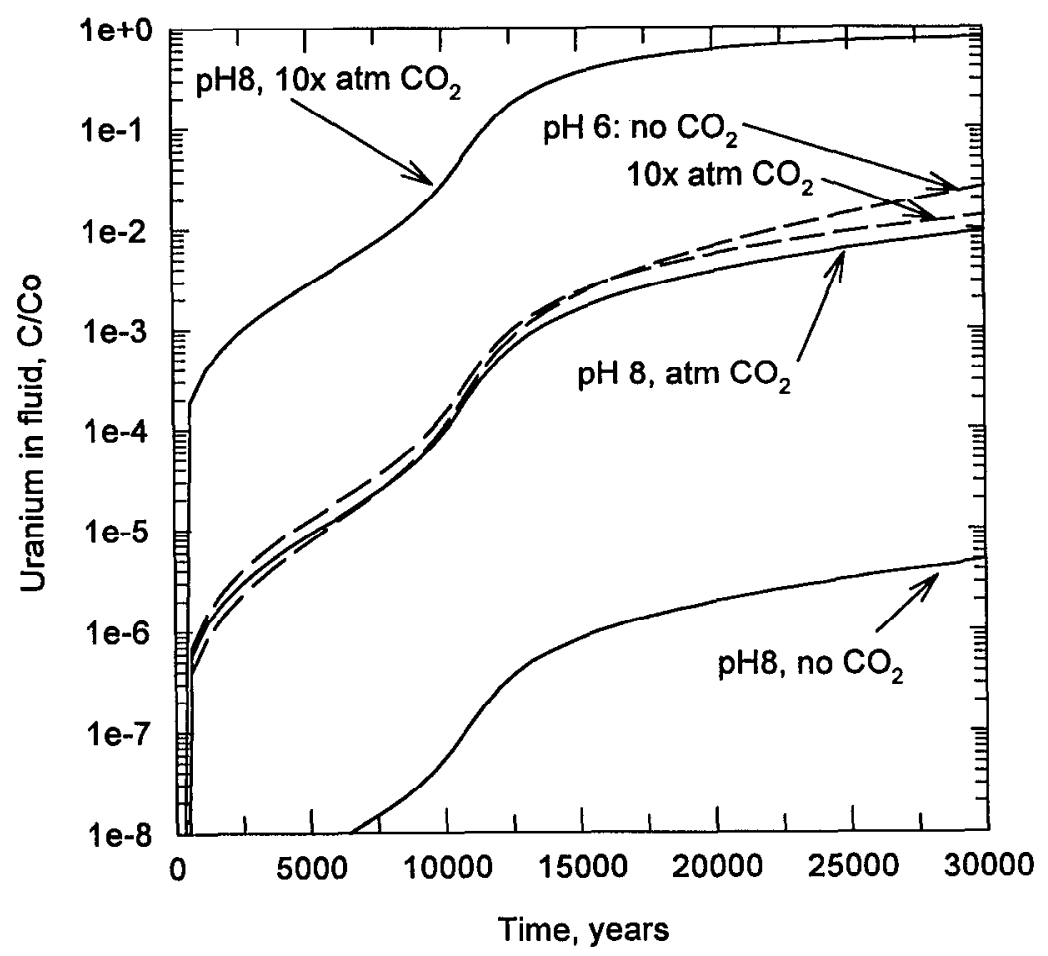

Figure 2. Variation in relative concentration of $U(C / C o)$ with time at node $\# 1,10 \mathrm{~cm}$ into hematite corrosion layer. 

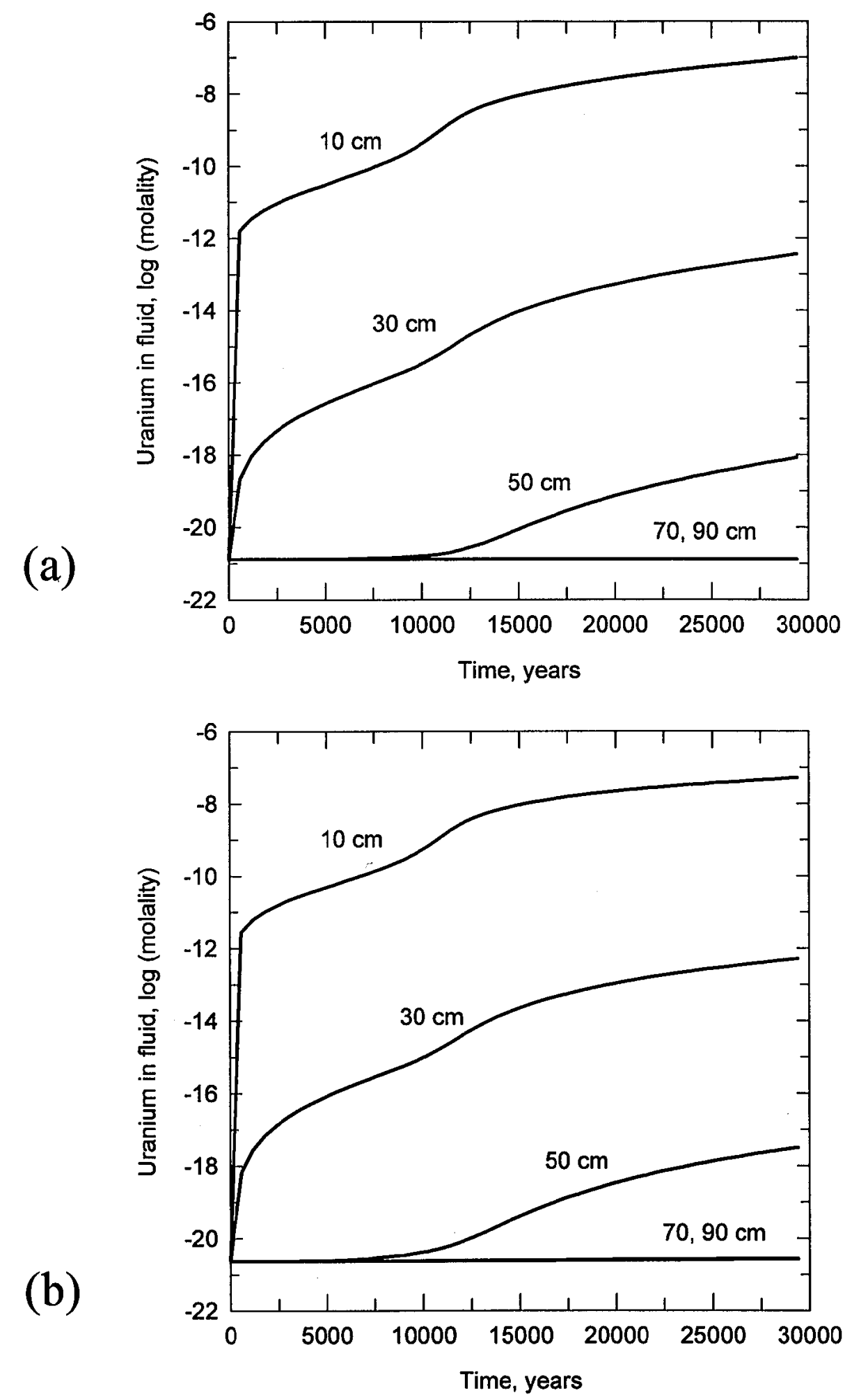

Figure 3. Variation in dissolved uranium concentration at 5 nodes for simulated transport of U-bearing solution: (a) $\mathrm{pH} 6$, no $\mathrm{CO}_{2}$; (b) $\mathrm{pH} \mathrm{6,10x} \mathrm{atm} \mathrm{CO}_{2}$. 

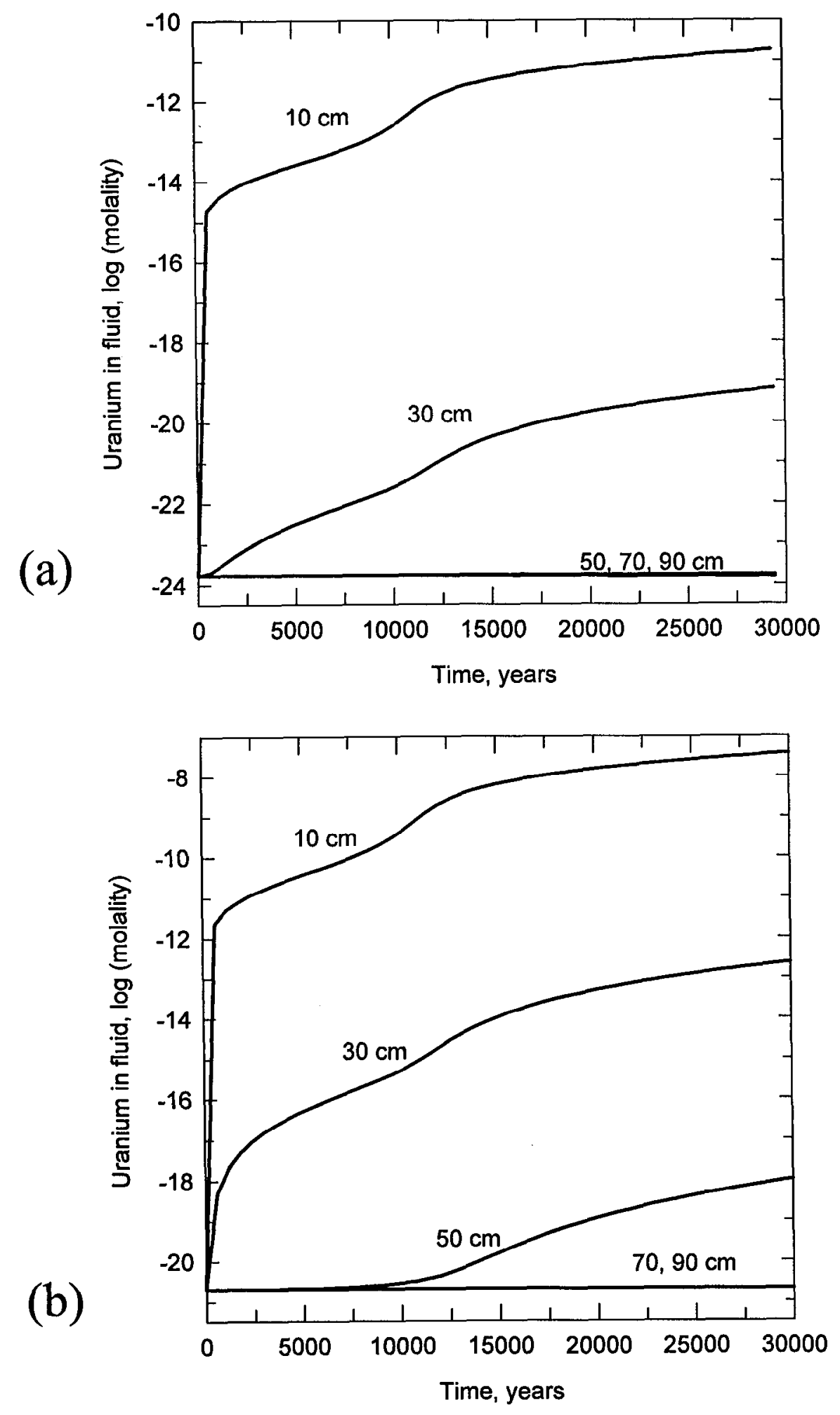

Figure 4. Variation in dissolved uranium concentration at 5 nodes for simulated transport of U-bearing solution: (a) $\mathrm{pH} 8$, no $\mathrm{CO}_{2}$; (b) $\mathrm{pH} 8$, atm $\mathrm{CO}_{2}$. 
Figure 6(a) shows the variation in $\mathrm{K}_{\mathrm{d}}$ as calculated from the simulated solution and sorbate compositions at the $10-\mathrm{cm}$ node for 4 simulations. The calculated $\mathrm{K}_{d}$ 's (especially at the earliest times) are very large, and they decrease by 2-3 orders of magnitude with time. The variation in time is directly related to surface site occupancy (Figure 6(b)). At

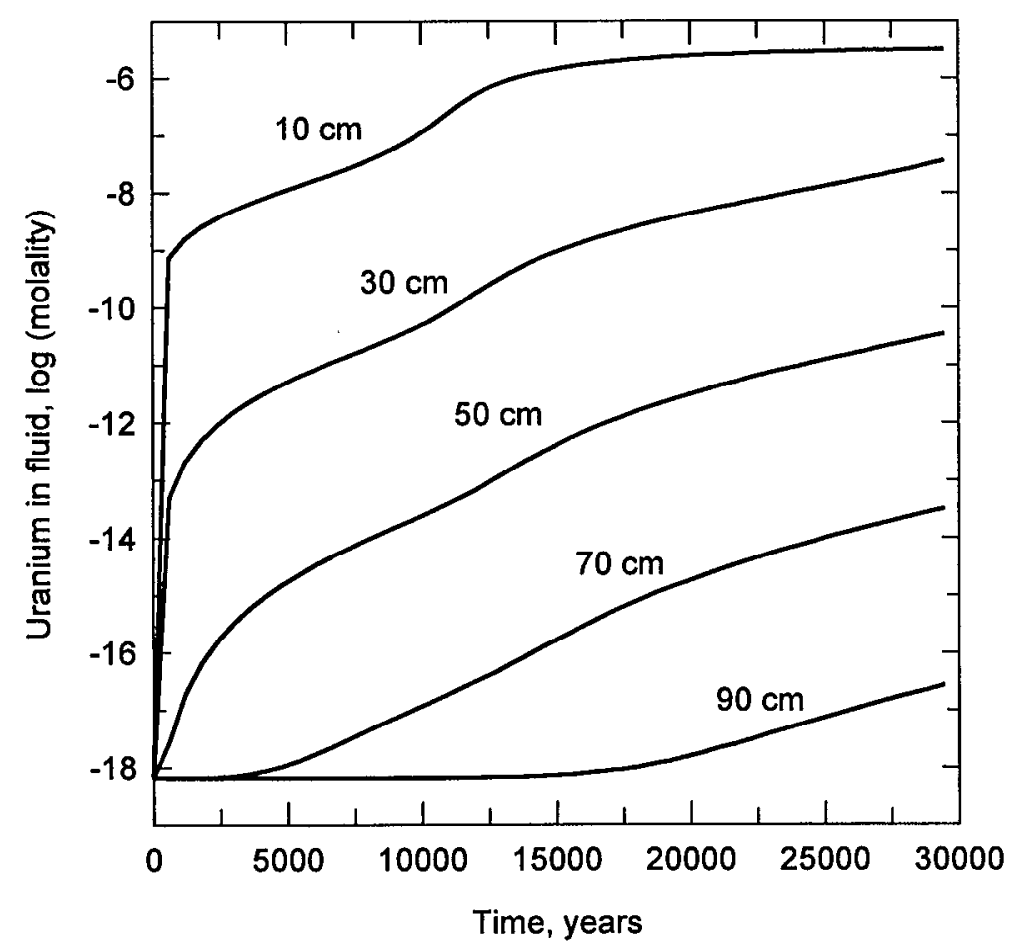

Figure 5. Variation in dissolved uranium concentration at 5 nodes for simulated transport of U-bearing solution ( $\mathrm{pH} \mathrm{8,10x} \mathrm{atm} \mathrm{CO}_{2}$ ).

$10-\mathrm{cm}$, the strong sites are completely filled by about 11 thousand years, and the weak sites are about $5 \%$ filled after 30 thousand years for the $\mathrm{pH} 6$ and $\mathrm{pH} 8$ (no $\mathrm{CO}_{2}$ and atmospheric $\mathrm{CO}_{2}$ ) cases. After the strong sites are filled, the $\mathrm{K}_{\mathrm{d}}$ drops by over an order of magnitude.

The calculated $K_{d}$ 's are much larger than those measured experimentally using batch techniques. The simulated concentrations of $U$ in the fluid at the earliest times are very low $\left(<10^{-12} \mathrm{M}\right)$, and the ratio of strong sites to dissolved $U$ is very large in the early stages of the simulation. It is unlikely that a batch experiment can be used to verify the very large $K_{d}$ 's predicted by the simulation because both the concentration of $U\left(<10^{-12} \mathrm{M}\right)$ and the solid/solution ratio $(\sim 8000 \mathrm{~g} / \mathrm{L})$ are not accessible experimentally. 
(a)
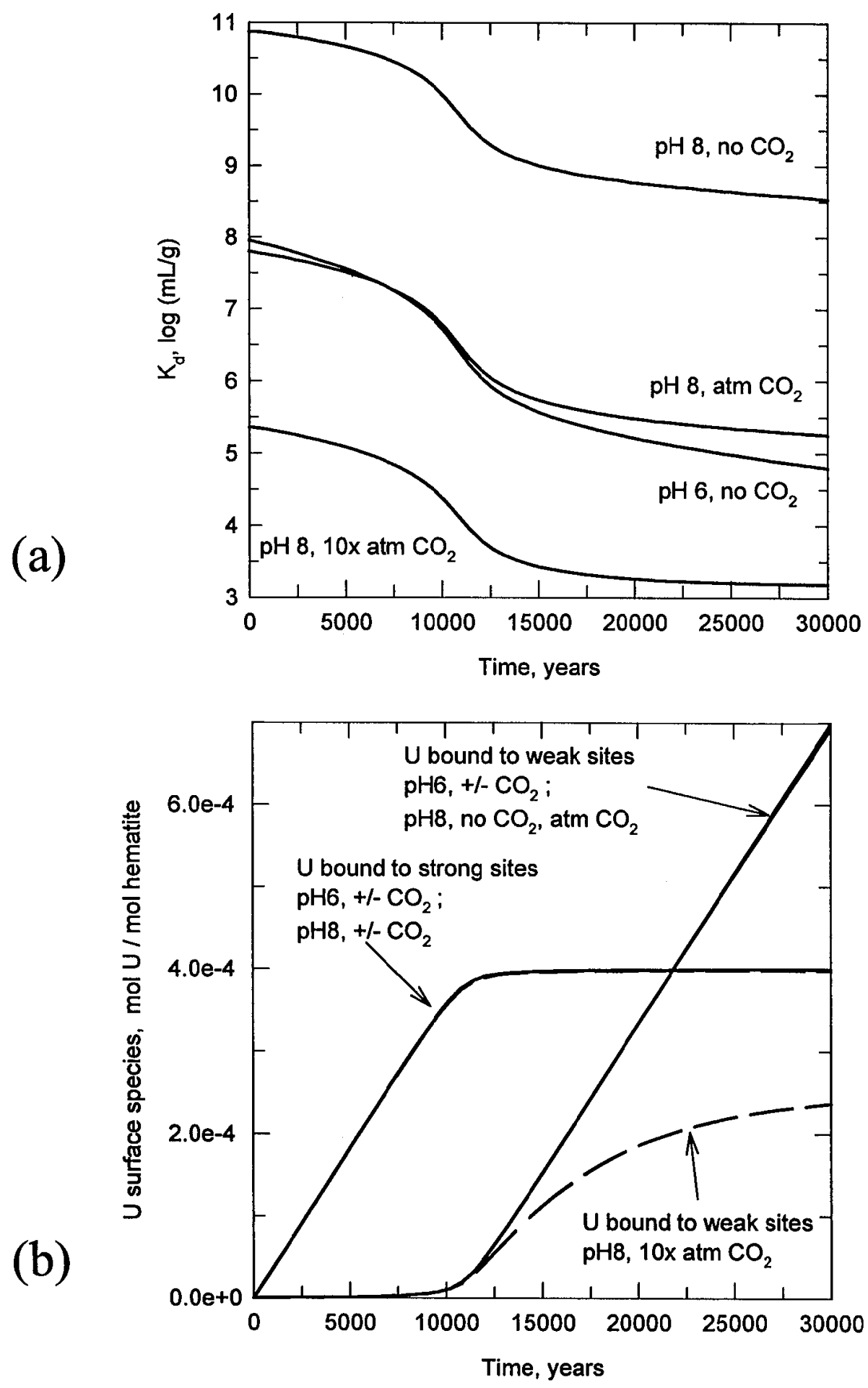

Figure 6. (a) Variation in $K_{d}$ vs. time at node \#1 (10-cm). (b) Concentration of $U$ vs. time on strong and weak sites at node \#1 $(10-\mathrm{cm})$. 
If $6 \mathrm{~L}$ of groundwater contacts the waste each year, the specific discharge used in the simulations requires a cross section equivalent to a circle with a diameter of about $65 \mathrm{~cm}$. A larger flux of groundwater or a smaller cross sectional area for flow would necessitate a larger specific discharge for the simulations. A larger specific discharge would yield a similar result but the time axis would be scaled downward accordingly (i.e., twice the discharge would result in breakthrough at half the time).

This analysis does not address the effect of competition for sorption sites or the effect of other solution ligands. Competition and solution complexation would reduce retardation. Retardation will be also be dependent on the volume of corrosion product contacted by the radionuclide-bearing groundwater. If groundwater flow is via unsaturated transport, the ratio of sorbent to sorbate would be larger than assumed in this calculation and retardation would be enhanced. The specific effects of $\mathrm{CO}_{2}$ are well known, however, the $\mathrm{CO}_{2}$ values expected in the repository are not well constrained.

\section{Cementitious Materials}

Under the expected repository design, concrete invert and pedestals will provide support for the waste canister. Hence, downward movement of radionuclide-bearing water will likely intercept these cementitious materials. Cementitious materials in the form of shotcrete or fibercrete may line the upper surfaces of the emplacement drifts and thus, alter the chemistry of water that transports radionuclides away from the canister and affect how it interacts with flow path components, such as iron oxides. The presence of concrete may result in decreased $\mathrm{CO}_{2}$ levels and increased $\mathrm{pH}$ and therefore would tend to enhance retardation by corrosion products. However, these chemical effects could largely be nullified by the time the waste canisters are breached, if the concrete has substantially altered to a mixture of carbonates and aluminosilicates.

To help define the role of concrete in controlling the transport of radionuclides through the Near Field Environment/Engineered Barrier System, experiments are being undertaken to measure $\mathrm{U}, \mathrm{Np}$, and I transport through samples of concrete from the invert used in the construction of the ESF. Fresh and heat-treated concretes will be used in the transport studies.

\section{Heat treatments applied to ESF concrete samples}

Concrete samples were heated (dry and hydrothermally) to alter the concrete to forms more likely to exist at the end of the dryout and rewetting periods, respectively. Although laboratory treatments such as these cannot reproduce the actual time/temperature/flowfield conditions expected in the repository, the treated samples are expected to be a more valid representation of the chemical and mineralogical properties of concrete that 
radionuclides may contact than fresh (untreated concrete). Both intact (fractured) and crushed concrete were heat treated according to the flow chart shown in Figure 7.

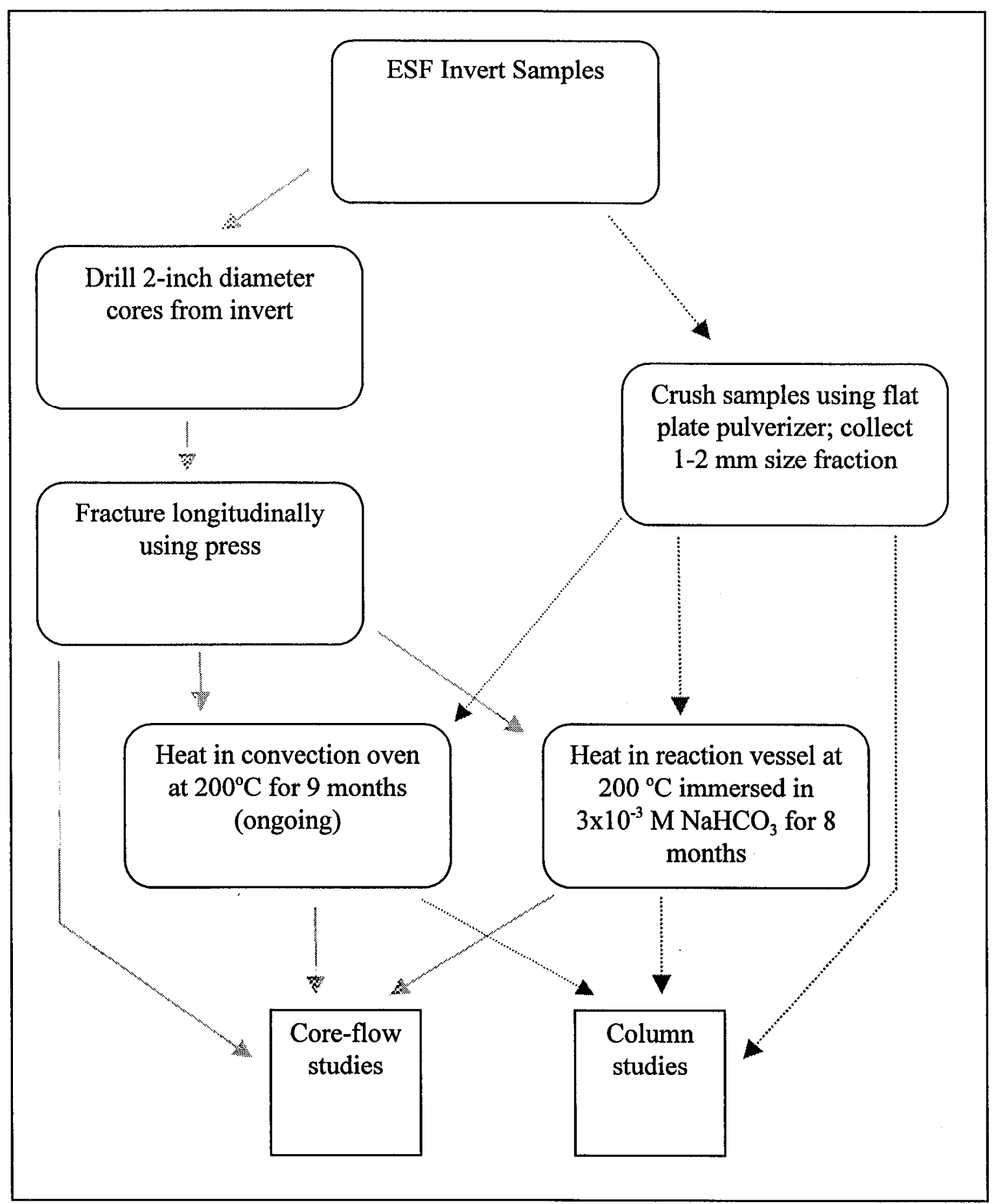

Figure 7. Flow chart showing the treatments applied to ESF concrete samples. 


\section{Characterization of fresh and hydrothermally altered concrete samples}

Samples of untreated and hydrothermally treated concrete were analyzed by xray diffraction and scanning electron microscopy. Preliminary results (Table 3) from these analyses indicate that the major mineralogical changes caused by the hydrothermal

Table 3. Phases identified by xray diffraction of untreated and hydrothermally altered concrete

\begin{tabular}{lll}
\hline Phase & Untreated concrete & $\begin{array}{l}\text { Hydrothermally treated } \\
\text { concrete }\end{array}$ \\
\hline Dolomite & major & major \\
Calcite & major & major \\
Quartz & minor & minor \\
Portlandite & major & not observed \\
Scawtite & not observed & minor \\
Tobermorite & not observed & minor \\
Xonotlite & not observed & minor \\
Smectite & not observed & minor \\
Serpentine & not observed & minor \\
\hline
\end{tabular}

${ }^{1}$ major, minor - qualitative assessment of the relative abundance of the phase based on xray peak intensities.

treatment are the disappearance of portlandite $\left(\mathrm{Ca}(\mathrm{OH})_{2}\right)$ and the appearance of the calcium silicate hydrate phases scawtite $\left(\mathrm{Ca}_{7} \mathrm{Si}_{6}\left(\mathrm{CO}_{3}\right) \mathrm{O}_{18} \cdot 2 \mathrm{H}_{2} \mathrm{O}\right)$, tobermorite $\left(\mathrm{Ca}_{5} \mathrm{Si}_{6}(\mathrm{OH})_{2} \cdot 4 \mathrm{H}_{2} \mathrm{O}\right)$, and xonotlite $\left(\mathrm{Ca}_{6} \mathrm{Si}_{6} \mathrm{O}_{17}(\mathrm{OH})_{2}\right)$, and clay mineral phases with the 2:1 layer structure (smectite) and 1:1 layer structure (serpentine).

It should be noted that because the aggregate used for the ESF invert is magnesium and carbonate rich (dolomitic limestone was used for the aggregate), the scawtite and serpentine phases that have been tentatively identified may not be the phases that would have been observed if the aggregate were composed of primarily aluminosilicate minerals. The formation of clays, especially smectite, is expected to significantly alter the sorptive capacity of the concrete for cationic radionuclides. 


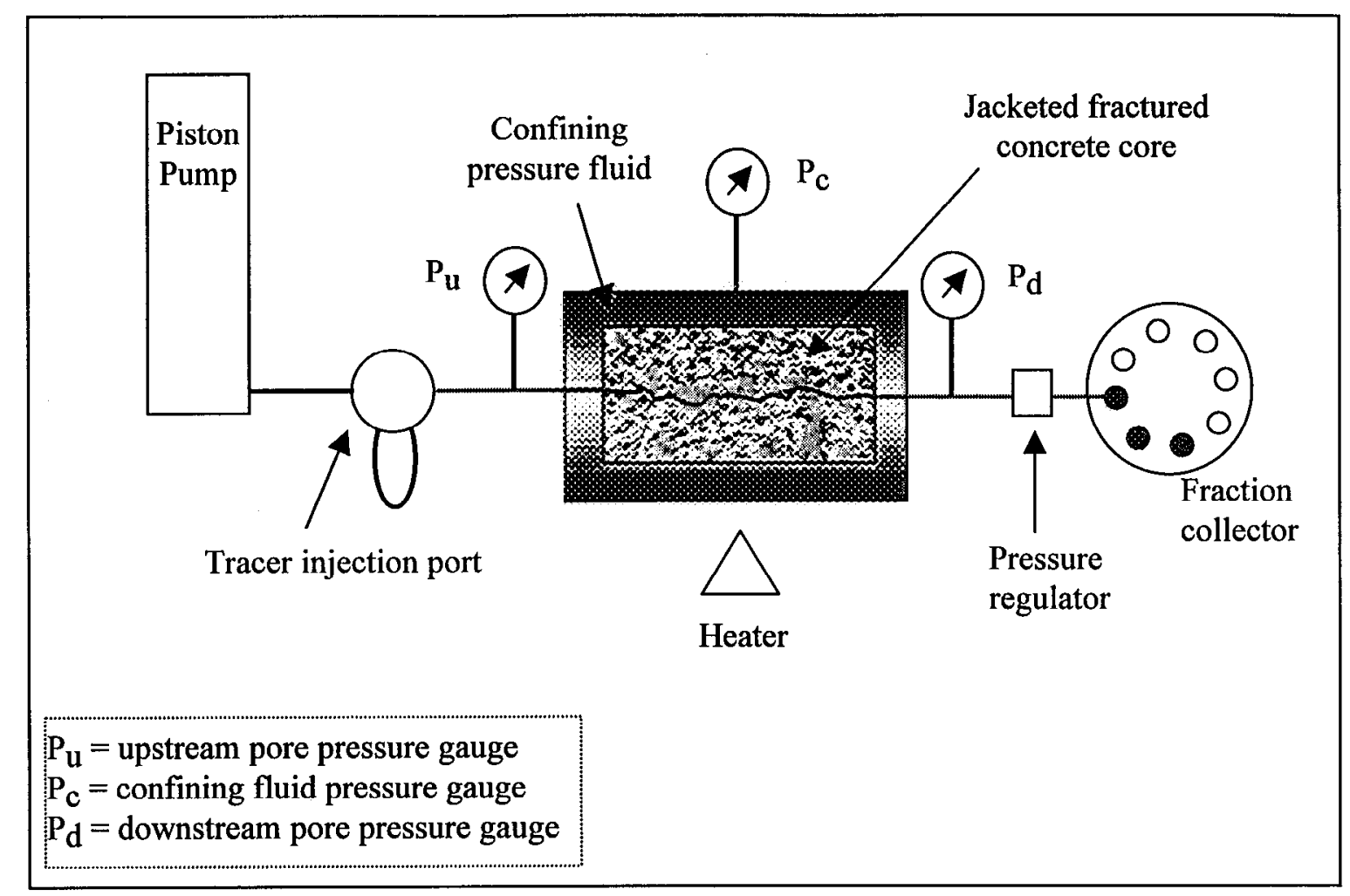

Figure 8. Schematic drawing of apparatus for transport experiments using intact fractured core samples.

\section{Core-flow experiment}

A fractured core that was hydrothermally treated was machined to 2 inches in length and installed into a core-flow device (Viani and Martin, 1994) that allows the introduction of tracer upstream from the core under either constant flow or constant pressure conditions (Figure 8 ). The jacketed core was placed under a confining pressure ( 35 bar) to prevent flow from occurring along the core boundaries. A dilute $\mathrm{NaCl}$ solution $(0.01 \mathrm{M})$ was passed through the core to establish baseline hydraulic information, and a pulse of $\mathrm{NaI}$ $\left(0.56 \mathrm{~mL}\right.$ of $\left.7.5 \times 10^{-4} \mathrm{M}\right)$ was injected upstream of the core to assess the transport of a conservative (non-retarded) species (Figure 9).

Although I' can be used as a conservative tracer for tuff and most sedimentary rocks (Viani and Carman, 1995), there is batch sorption data for cementitious materials (not hydrothermally treated) indicating that $I^{-}$may not be conservative $\left(\mathrm{K}_{\mathrm{d}}\right.$ 's between 10 and $600 \mathrm{~mL} / \mathrm{g}$ ) (Atkins and Glasser, 1990; Baker et al., 1994; Heath et al., 1996). The sorption of I will be independently assessed by batch studies using hydrothermally altered and untreated ESF concrete. 


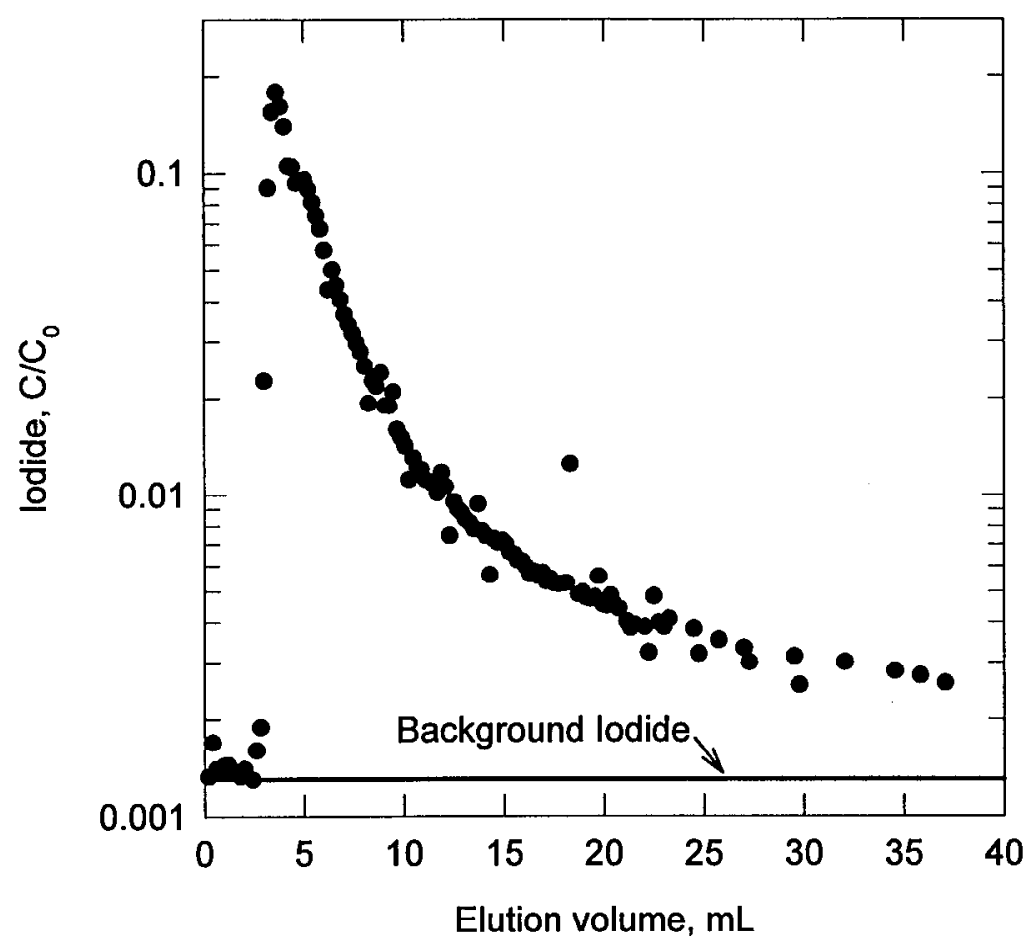

Figure 9. Relative concentration of iodide $\left(\mathrm{C} / \mathrm{C}_{\mathrm{o}}\right)$ in $0.01 \mathrm{M} \mathrm{NaCl}$ effluent from fractured, hydrothermally altered concrete core. A $0.560 \mathrm{~mL}$ pulse of $7.5 \times 10^{-4}$ molar NaI $\left(\mathrm{C}_{\mathrm{o}}\right)$ was injected at $0 \mathrm{~mL}$ elution volume. Background $\mathrm{C} / \mathrm{C}_{\mathrm{o}}$ was assumed equal to the lowest measured value prior to breakthrough $\left(1.3 \times 10^{-3}\right)$. The area under the breakthrough curve, but above background, equals $0.520 \mathrm{~mL}$, or $\sim 93 \%$ of the injected iodide.

The breakthrough of $I^{-}$through the fractured concrete is similar to that previously observed for a saw-cut tuff (Viani and Carman, 1995), except that greater diffusion and/or advection into the concrete matrix, or sorption by the matrix, has resulted in a longer 'tail' on the trailing edge of the breakthrough curve. Approximately $7 \%$ of the injected $\mathrm{I}^{-}$ was not eluted after $40 \mathrm{~mL}$ of carrier fluid had been passed through the core. This fraction is thought to represent $\mathrm{I}^{-}$that has diffused into the matrix and is slowly diffusing out into the $\mathrm{I}^{-}$free $\mathrm{NaCl}$ carrier solution. The results of the batch sorption experiments will be required to assess whether sorption of $\mathrm{I}^{-}$has occurred on this concrete during transport, and whether it is significant enough to affect the observed breakthrough curve.

\section{Effect of cementitious material on $U$ transport through iron oxides}

A preliminary assessment of the effect of cementitious material on $U$ transport through a corrosion product layer was made using model simulations. Model parameters were the 
same as described above, but input solution compositions were adjusted to simulate the effect of concrete on fluid chemistry (Table 4). For the simulation using 'cement water', two $\mathrm{Ca}$ surface species were added to the model to assess the effect of competitive adsorption. The Ca surface species, and the $\log \mathrm{K}_{\mathrm{B}}$ 's for the following surface complexation reactions at weak and strong sites were taken from Dzombak and Morel (1990),

$$
\begin{array}{lll}
>(\mathrm{w}) \mathrm{FeOH}^{\circ}+\mathrm{Ca}^{++}= & >(\mathrm{w}) \mathrm{FeOCa}^{+}+\mathrm{H}^{+} & \log \mathrm{K}_{\mathrm{B}}=-5.85 \\
>(\mathrm{s}) \mathrm{FeOH}^{\mathrm{o}}+\mathrm{Ca}^{++}= & >(\mathrm{s}) \mathrm{FeOHCa}^{++} & \log \mathrm{K}_{\mathrm{B}}=10.45
\end{array}
$$

where $>(w)$ and $>(s)$ refer to weak and strong sites, respectively.

Table 4. Composition of fluids used for assessing the effect of a high $\mathrm{pH}$ cementitious

\begin{tabular}{|c|c|c|c|c|}
\hline \multirow[b]{2}{*}{$\begin{array}{l}\text { Inlet Fluid } \\
\text { Composition }\end{array}$} & \multicolumn{4}{|c|}{ Simulation } \\
\hline & $\begin{array}{l}\mathrm{pH} 10, \\
\text { no } \mathrm{CO}_{2}\end{array}$ & $\begin{array}{l}\mathrm{pH} 10 \\
\mathrm{~atm} \mathrm{CO}\end{array}$ & $\begin{array}{l}\mathrm{pH} 10 \\
10 \times \mathrm{CO}_{2}\end{array}$ & $\begin{array}{l}\text { 'Cement } \\
\text { Water'(1) }\end{array}$ \\
\hline $\mathrm{pH}$ & 10 & 10 & 10 & 12.17 \\
\hline $\mathrm{CO}_{2}$, fugacity & 0.0 & 0.0003 & 0.003 & $5.04 \times 10^{-13}$ \\
\hline $\mathrm{O}_{2}$, fugacity & 0.20 & 0.20 & 0.20 & 0.20 \\
\hline Ionic strength, $\mathrm{M}$ & 0.01 & 0.357 & 12.3 & 0.232 \\
\hline $\mathrm{Na}, \mathrm{M}$ & 0.01 & 0.298 & 22.4 & 0.200 \\
\hline $\mathrm{Ca}, \mathrm{M}$ & $\mathrm{nc}^{(2)}$ & $\mathrm{nc}$ & $\mathrm{nc}$ & 0.0139 \\
\hline $\mathrm{Al}, \mathrm{M}$ & nc & nc & nc & $1.78 \times 10^{-5}$ \\
\hline $\mathrm{U}, \mathrm{M}$ & $4.00 \times 10^{-6}$ & $4.00 \times 10^{-6}$ & $4.00 \times 10^{-6}$ & $4.00 \times 10^{-6}$ \\
\hline $\mathrm{SiO}_{2}, \mathrm{M}$ & nc & $\mathrm{nc}$ & nc & $3.13 \times 10^{-6}$ \\
\hline $\mathrm{Cl}, \mathrm{M}$ & 0.0099 & 0.01 & 0.01 & 0.200 \\
\hline $\mathrm{SO}_{4}, \mathrm{M}$ & $\mathrm{nc}$ & nc & $\mathrm{nc}$ & $1.85 \times 10^{-3}$ \\
\hline
\end{tabular}
material on transport of $U$ through a hematite corrosion product layer.

(1) The composition of this fluid is based on the $\mathrm{Ca}, \mathrm{Al}, \mathrm{SiO}_{2}$, and $\mathrm{SO}_{4}$ predicted for a solution in equilibrium with typical cement phases: calcite, hillebrandite, katoite, ettringite, portlandite and hematite. The $\mathrm{NaCl}$ concentration was set to $0.2 \mathrm{M}$ (similar to that observed by Atkins et al. (1994) for an ordinary portland cement). The $\mathrm{pH}$ and fugacity of $\mathrm{CO}_{2}$ were calculated using the React geochemical modeling code (data: thermo.com.V8.R6.230) by adjusting $\mathrm{OH}^{-}$to maintain electrical neutrality, and by constraining the fugacity of $\mathrm{CO}_{2}$ by equilibrium with calcite.

(2) nc - component not considered in simulation. 


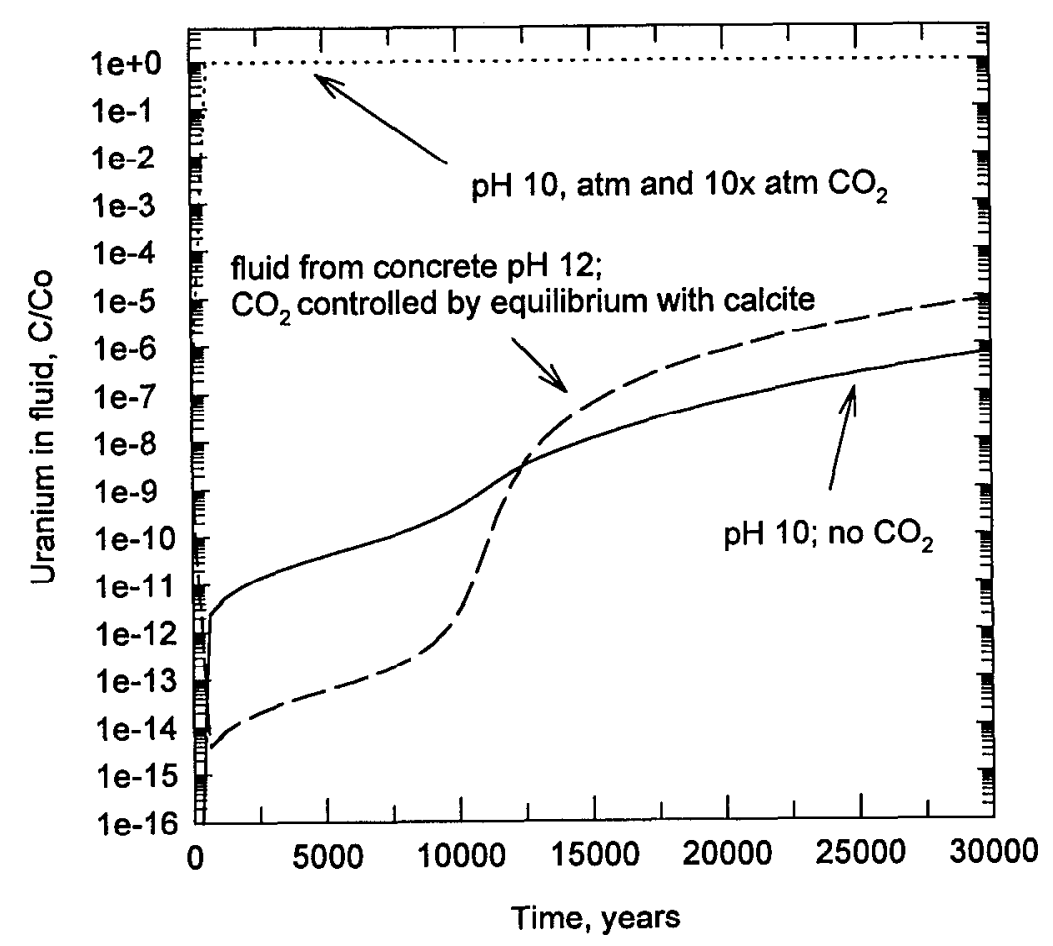

Figure 10. Variation in relative concentration of $U(C / C o)$ with time at node $\# 1,10 \mathrm{~cm}$ into hematite corrosion layer.

$\mathrm{pH}$ and $\mathrm{CO}_{2}$ Effects - Waters with $\mathrm{pH}$ of 10 were used to simulate a groundwater whose $\mathrm{pH}$ had been elevated by interaction with cement, but not raised to the $\mathrm{pH}$ 's observed for fresh concrete $(\mathrm{pH}>12)$. These simulations can be compared directly with the simulations described above run at lower pHs. It is clear that maintaining a pH of 10 and $\mathrm{aO}_{2}$ fugacity equal to 10 times that of atmospheric is not likely (e.g., the ionic strength required would be greater than $10 \mathrm{M}$ !). The simulation under this scenario is not considered realistic, but is included for comparison purposes. In fact, at a $\mathrm{pH}$ of 10 , the simulated transport of $U$ through a hematite corrosion layer is the same for the atmospheric and $10 \mathrm{x}$ atmospheric $\mathrm{CO}_{2}$ levels (Figure 10). At $\mathrm{pH} 10$ at atmospheric and 10x atmospheric levels, breakthrough of $U$ is essentially immediate, i.e., under these conditions $U$ behaves as a conservative species with respect to sorption. At $\mathrm{pH} 10$ in the absence of $\mathrm{CO}_{2}, \mathrm{U}$ is significantly retarded, and breakthrough would be more delayed than at lower $\mathrm{pHs}$ in the absence of $\mathrm{CO}_{2}$ (compare with Figure 2). 
Transport of $U$ through the corrosion layer for a groundwater having the composition shown in the last column of Table 4 ('cement water') is similar to that at $\mathrm{pH} 10$ in the absence of $\mathrm{CO}_{2}$. The simulation of $\mathrm{U}$ transport in water derived from interaction of groundwater with cement was modeled assuming that $\mathrm{CO}_{2}$ levels were controlled by equilibrium with calcite. Under these conditions, the $\mathrm{pH}$ is fixed by the concrete chemistry and the $\mathrm{CO}_{2}$ concentration is quite low. This composition might be expected to describe a fluid in the pore space of the concrete or at the point the fluid exits the concrete. The rock properties rather than the gas properties in this case control the fluid composition. In contrast, for a fluid having extensive contact with a reservoir of $\mathrm{CO}_{2}$, the

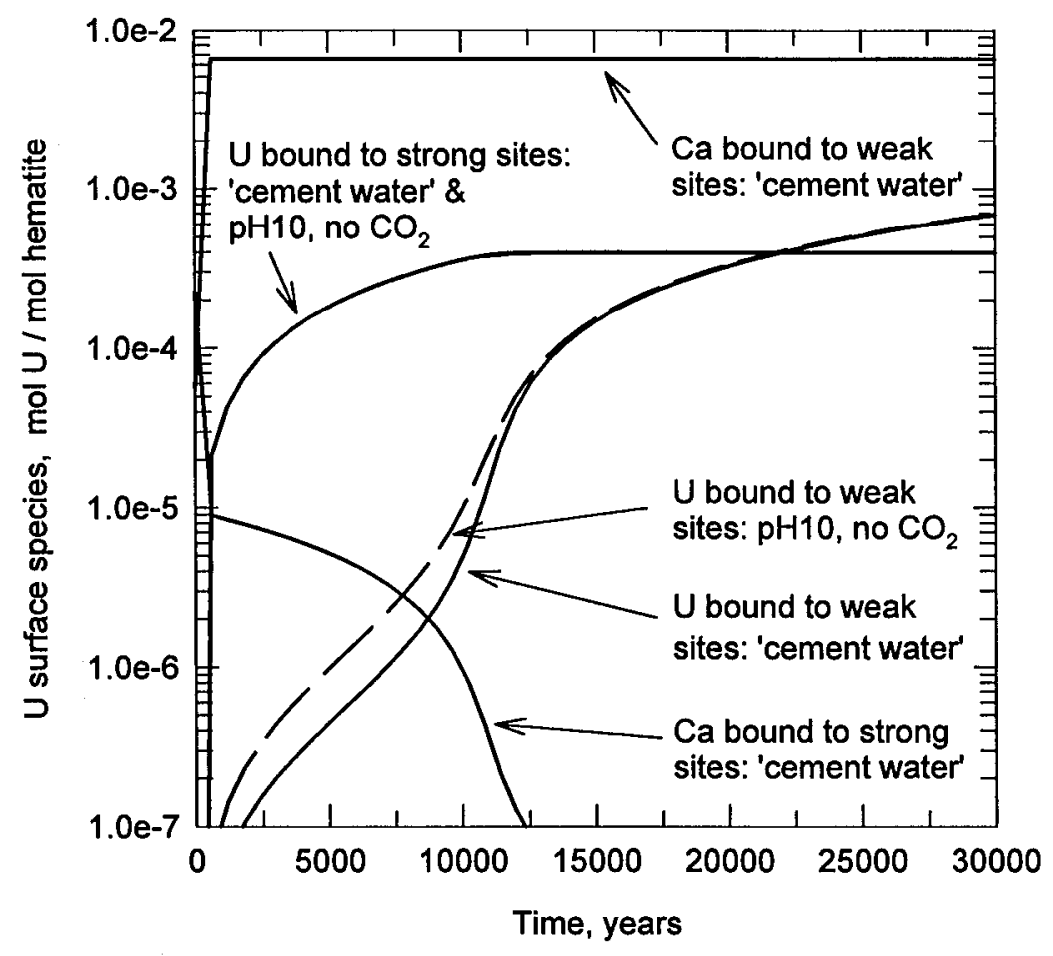

Figure 11. Variation in concentration of $\mathrm{U}$ and $\mathrm{Ca}$ surface species with time at node \#1 $(10-\mathrm{cm})$ in hematite corrosion layer for $\mathrm{pH} 10\left(\right.$ no $\left.\mathrm{CO}_{2}\right)$ and cement-derived ground waters.

$\mathrm{pH}$ would be expected to be significantly lower, probably controlled by calcite equilibria. Under this scenario, for the same fluid composition shown in Table 4, the $\mathrm{pH}$ would be 8.15 for equilibrium with atmospheric $\mathrm{CO}_{2}$ and calcite. Transport of $\mathrm{U}$ under those conditions would be expected to be similar to the $\mathrm{pH} 8$ atm $\mathrm{CO}_{2}$ simulation shown in Figures 2 and 4(b); that is, retardation of $U$ would still be quite significant.

Effect of Ca Sorption - The effect of Ca sorption on $\mathrm{U}$ sorption appears to be minimal in these simulations as judged by a comparison of the concentration of surface $U$ species for the $\mathrm{pH} 10$ (no $\mathrm{CO}_{2}$, no $\mathrm{Ca}$ ) and 'cement water' results (Figure 11). Note that the 
concentrations of surface species in Figure 11 are plotted logarithmically so as show both the Ca surface species concentrations and the U surface species on the same plot. Even in the presence of a large amount of sorbed $\mathrm{Ca}$, sorption of $\mathrm{U}$ onto strong and weak sites is almost identical to that predicted in the $\mathrm{pH} 10$ simulation. The concentrations of surface $\mathrm{U}$ species shown in Figure 11 are essentially identical to those for the $\mathrm{pH} 6$ and $\mathrm{pH} 8$ (no and atm $\mathrm{CO}_{2}$ ) simulations shown in Figure 6(b).

\section{Conclusions}

Iron oxides derived from the corrosion allowance layer of the waste canister have the potential to provide a sorptive barrier to radionuclide transport that is equivalent to thousands of meters of surrounding rock. Thus, there is a potential for retardation of radionuclides, relative to a conservative tracer, for time periods of thousands to tens of thousands of years following release from the waste canister. However, retardation will be strongly affected by fluid chemistry, particularly, $\mathrm{pH}$ and $\mathrm{CO}_{2}$, and by the area and length of the flow path through the corrosion layer.

Model results indicate that at high $\mathrm{pH}$, the presence of significant levels of $\mathrm{CO}_{2}$ can destroy the capacity of the corrosion product layer to sorb $\mathrm{U}$. The levels of $\mathrm{CO}_{2}$ expected in the repository and in the groundwater at the time of radionuclide transport are not well constrained. The presence of large masses of cementitious materials may prevent $\mathrm{CO}_{2}$ levels from being higher than atmospheric if the cement is not completely carbonated prior to breaching of the waste canisters. However, the simulations suggest retardation will remain significant for two scenarios that may control fluid chemistry: 1) High pH fluids in which $\mathrm{CO}_{2}$ fugacity is controlled by calcite equilibria (e.g. fluids within a cementitious material), and; 2) Initially high $\mathrm{pH}$ fluids whose $\mathrm{pH}$ is reduced by subsequent equilibrium with calcite at the ambient $\mathrm{CO}_{2}$ fugacity (e.g., fluids that have interacted with and exited a cementitious material).

Although the emphasis in these studies is the sorptive behavior of ncar ficld materials, simulations that include precipitation and dissolution phenomena will have to be considered to obtain a more realistic assessment on radionuclide migration through altered concrete. Based on these preliminary analyses, the presence of corrosion products in the flow field down gradient from the waste canisters will significantly affect repository performance in a positive way. Source terms that do not account for the interaction of radionuclides with these materials may overestimate the flux of radionuclides to the far field. 


\section{References}

Atkins, M., and Glasser, F.P. 1990. Encapsulation of radioiodine in cementitious waste forms. In Oversby, V.M. and Brown, P.W. (eds) Scientific Basis for Nuclear Waste Management XIII. Mat. Res. Soc. Symp. Proc. Vol. 176:15-22.

Atkins, M., Damidot, D., and Glasser, F.P. 1994. Performance of cementitious systems in the repository. In Barkatt, A. and Van Konynenburg, R.A. (eds) Scientific Basis for Nuclear Waste Management XVII. Mat. Res. Soc. Symp. Proc. Vol. 333:315-326.

Baker, S., McCrohon, R., Oliver, P., and Pilkington, N.J. 1994. The sorption of niobium, tin, iodine, and chlorine onto NIREX reference vault backfill. In Barkatt, A. and Van Konynenburg, R.A. (eds) Scientific Basis for Nuclear Waste Management XVII. Mat. Res. Soc. Symp. Proc. Vol. 333:719-724.

Bethke, C.M. 1994. A Users Guide to Rxn, Act2, Tact, React, and Gtplot. Copyright Craig M. Bethke, University of Illinois, Champaign, IL.

Bethke, C.M. 1996. Reactive Transport and Basin Modeling. Short Course Workbook. Hydrogeology Program, University of Illinois, Champaign, IL May 29-31, 1996.

Davis, J. A., and Kent, D. B. 1990. Surface complexation modeling in aqueous geochemistry. Mineral-Water Interface Geochemistry. (eds.) Hochella, M. F. and White, A. F., Washington, D.C., Mineralogical Society of America. 23: 177-260.

Dzombak, D. A., and Morel, F. M. 1990. Surface Complexation Modeling: Hydrous Ferric Oxide. New York, New York.

Heath, T.G., Ilett, D.J., and Tweed, C.J. 1996. Thermodynamic modelling of the sorption of radioelements onto cementitious materials. In Murphy, W.M. and Knecht D.A. (eds) Scientific Basis for Nuclear Waste Management XLX. Mat. Res. Soc. Symp. Proc. Vol. 412:443-449.

Ticknor, K.V. 1994. Uranium sorption on geological materials. Radiochimica Acta 64:229-236.

Turner, D.R. 1995. A Uniform Approach to Surface Complexation Modeling of Radionuclide Sorption. Center for Nuclear Waste Regulatory Analyses, San Antonio, TX CNWRA 95-001.

Viani, B.E. 1996. Materials To Be Used For Radionuclide Transport Experiments. YMP Milestone SPL3A1M4.

Viani, B.E., and Torretto, P.C. 1997. Sorption and Transport of Uranium on Hematite. YMP Milestone SPL3BM4. 
Viani, B.E., and Carman, M.L 1995. Transport of Soluble Species Through Tuff Core. YMP Milestone MOL52.

Viani B.E. and Martin, S.I. 1994. Core Flow Experiment Protocol. YMP Milestone Report M0L04. 


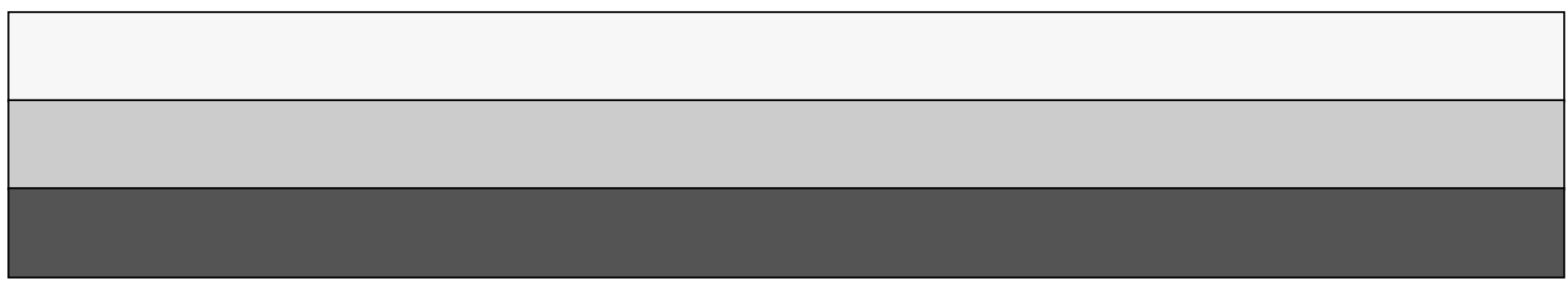

